\title{
Screening for activating EGFR mutations in surgically resected nonsmall cell
}

\section{lung cancer}

\author{
K.B. Sriram*,\#, M.E. Tan", S.M. Savarimuthu*\#, C.M. Wright*,", V. Relan*,\#, \\ R.E. Stockwell , B.E. Clarke", E.E. Duhig", I.A. Yang*,", \\ R.V. Bowman*,\# and K.M. Fong*,\#
}

ABSTRACT: The clinical applicability of screening surgically resected nonsmall cell lung cancer (NSCLC) tumour tissue and serum for activating epidermal growth factor receptor (EGFR) mutation is unknown. Furthermore, the comparative accuracy of inexpensive EGFR mutation tests, mutant-enriched (ME)-PCR and high-resolution melt (HRM) has not been determined.

Lung tumour DNA from 522 surgically resected stage I-IV NSCLC and matched serum DNA from a subset of 64 subjects was analysed for EGFR mutations in exons 19 and 21 using ME-PCR and HRM. Additionally, 97 subjects had previous EGFR DNA sequencing data available for comparison.

ME-PCR and HRM detected EGFR mutations in 5\% (27 out of 522) of tumour samples. Compared to DNA sequencing, ME-PCR had a sensitivity of $100 \%$ and specificity of $99 \%$, while HRM had $100 \%$ sensitivity and specificity. Six subjects with EGFR mutation tumours had matched serum, where ME-PCR detected mutations in three samples and HRM in two samples. In the cohort of never-smoker subjects, those with EGFR mutated tumours had worse survival compared with wild-type tumours (30 versus 49 months; $p=0.017$ ).

ME-PCR and HRM have similar accuracy in detecting EGFR mutations but the prognostic implications of the mutations in resected NSCLC warrants further study.

KEYWORDS: Epidermal growth factor receptor, high-resolution melt analysis, mutant-enriched PCR, nonsmall cell lung cancer, prognosis, somatic mutations

ung cancer is a global health problem, resulting in about 1 million deaths annually [1]. Nonsmall cell lung cancer (NSCLC) is the most common histological subtype, accounting for $80 \%$ of lung cancer diagnoses. The prognosis for NSCLC continues to remain poor, with a 5 -yr survival of $15 \%$. Even in early stage NSCLC (stages I and II), after patients undergo surgical resection of the tumour, recurrence of the primary tumour in stage I NSCLC occurs in 30-35\% [2]. Platinum-based adjuvant chemotherapy has been shown to improve survival in stages II and IIIA, but the benefit in stage I patients is contentious [3].

Recently, in advanced NSCLC, the introduction of epidermal growth factor receptor (EGFR) tyrosine kinase inhibitors (TKIs) (gefitinib and erlotinib) has demonstrated improvements in clinical outcomes, particularly in subjects with mutant EGFR tumours [4-6]. A 15-bp deletion involving amino acid residues leucine 747 to glutamic acid 749 in exon 19 (DEL) and a point mutation substituting arginine for leucine at codon 858 (L858R) in exon 21 account for 44 and $41 \%$, respectively, of NSCLC EGFR mutations [7]. These mutations are associated with TKI responsiveness, occur in the ATP-binding pocket of the tyrosine kinase domain of EGFR and are referred to as "activating" mutations [8]. But while screening for activating EGFR mutations in advanced NSCLC has important clinical implications, the clinical utility of this strategy in early stage NSCLC subjects undergoing surgical resection is controversial, with studies providing conflicting results. While some studies have not identified a relationship between EGFR mutation status and overall survival [9-13], others suggest better survival among EGFR mutation subjects [6, 14]. Furthermore, recent studies have demonstrated that subjects with activating EGFR mutations may
AFFILIATIONS

*UQ Thoracic Research Centre, School of Medicine, The University of Queensland,

\#Dept of Thoracic Medicine, and 'Dept of Anatomical Pathology, The Prince Charles Hospital, Brisbane, Australia.

CORRESPONDENCE

K.B. Sriram

Dept of Thoracic Medicine The Prince Charles Hospital Rode Road Chermside Brisbane Queensland 4032 Australia E-mail: bajee.sriram@ uqconnect.edu.au

Received: Dec 092010 Accepted after revision: Feb 082011 First published online: Feb 242011 
derive benefit, albeit nonsignificant, from adjuvant chemotherapy $[9,15]$. Hence, it is important to evaluate the utility of screening for EGFR mutations in this population, since the presence of activating mutations may not only determine prognosis but may be predictive of TKI responsiveness, either as adjuvant therapy or in situations of tumour recurrence.

The classic method of detecting EGFR mutations is dideoxynucleotide sequencing. However, uptake of DNA sequencing for routine testing is impeded by relatively high cost, and the need for sophisticated equipment and technical expertise, which are often only available in specialised molecular pathology laboratories. Additionally, DNA sequencing cannot be used to accurately detect EGFR mutations in low tumour content samples which have $<20 \%$ mutant allele content [16]. This would limit the applicability of DNA sequencing to test for EGFR mutations in instances such as tumour recurrence, in which it is often challenging to obtain tumour tissue for mutation analysis. Hence, there is growing interest in testing serum samples from NSCLC subjects for EGFR mutations [17]. Recently, novel molecular methods have been developed to accurately detect EGFR mutations in NSCLC tumour tissue and low tumour content samples [16]. Two such methods are mutant-enriched (ME)-PCR and high-resolution melt (HRM). ME-PCR uses restriction enzymes to selectively digest wildtype EGFR alleles and amplify mutant alleles [18]. ME-PCR can detect EGFR mutations in tissue and serum samples [19]. However, ME-PCR requires manual handling and can be subject to false positive results. Conversely, HRM does not require manual handling due to a closed tube format and is more time efficient than ME-PCR. HRM has $>90 \%$ sensitivity and specificity in tumour tissue [20], but the diagnostic accuracy of HRM in serum samples has not been evaluated.

In this single-centre retrospective study, we evaluated surgically resected lung tumour tissue from 522 subjects with primary NSCLC, for the presence of EGFR exon 19 DEL and exon 21 mutations using ME-PCR and HRM. We also studied matched serum samples to determine the feasibility of using ME-PCR and HRM for the detection of EGFR mutations in a subset of 64 subjects. The relationship between EGFR mutation status and clinico-pathological factors, including overall survival after resection of primary NSCLC, was also evaluated.

\section{MATERIALS AND METHODS \\ Samples}

Fresh frozen surgically resected tumour tissue was obtained from subjects who donated remnant tissue samples to The Prince Charles Hospital, Brisbane, Australia between 1992 and 2009. Whenever possible, matched blood samples from the subjects were collected. DNA was extracted from the serum in the blood samples. The study was approved by the human research ethics committees at The Prince Charles Hospital and The University of Queensland, Brisbane, Australia. Additional detail on study samples is provided in the online supplementary material.

\section{Dilution assays}

Dilution studies were performed using American Tissue Cell Collection (Manassas, VA, USA) lung cancer cell lines, H1650 and H1975, which harbour a DEL and L858R mutation, respectively [21]. H1650 and H1975 DNA was mixed with human female genomic DNA (Promega, Sydney, Australia) (EGFR wild type) in $50 \%, 10 \%, 5 \%, 2.5 \%$ and $0.5 \%$ dilutions.

\section{ME-PCR assay}

We found it necessary to optimise the original ME-PCR assays [18] to suit the equipment, conditions and reagents used in our laboratory. EGFR exon 19 DEL experiments consisted of PCR amplification followed by digestion by MseI. PCR amplification was performed using ATCCCAGAAGGTGAGAAAGA TAAAATTC (forward primer, exon 19-S1) and CCTGAGGT TCAGAGCCATGGA (reverse primer, exon 19-S1). The final product was analysed using $12 \%$ polyacrylamide gel electrophoresis where the 88-bp band represented the DEL allele and the 100-bp band represented the wild-type allele.

EGFR exon 21 L858R experiments were performed using two rounds of PCR amplification interspersed with digestion steps using MscI and Sau96I, respectively. PCR amplification was performed using CAGCCAGGAACGTACTGGTGA (forward primer, exon 21-S1), CGCAGCATGTCAAGATCACAGAT (forward primer, exon 21-S2) and TCCCTGGTGTCAGGAAAAT GCT (reverse primer, exon 21-AS1). The final products were analysed using $4 \%$ agarose gel electrophoresis where the 99-bp band represented the L858R allele and the 130-bp band represented the wild-type allele. Additional detail on the method and the modifications from the original ME-PCR method are provided in the online supplementary material.

\section{HRM analysis}

HRM methods and primers were adapted from published protocols [20]. The primers for EGFR exon 19 forward are: GTGCATCGCTGGTAACATCCA; and reverse: AAAGGTGG GCCTGAGGTTCA; and for EGFR exon 21 forward: CCTCAC AGCAGGGTCTTCTCTG; and reverse: TGGCTGACCTAAAG CCACCTC. Each experiment was run with an EGFR wild-type control (human female genomic DNA) and a mutation-positive control sample. Normalised and difference curves were used to interpret the HRM results. Samples revealing skewed curves similar to the positive controls were deemed to harbour mutations. Additional detail on the method is provided in the online supplementary material.

\section{DNA sequencing}

DNA sequencing of EGFR exons 19 and 21 was available for 97 of the 522 subjects (part of a prior study) [11]. Separately, DNA sequencing was also used to confirm the mutation-positive samples identified by either ME-PCR or HRM. Bidirectional sequencing was performed at the Australian Genome Research Facility (Brisbane, Australia) using the HRM forward and reverse primers.

\section{Statistical analysis}

We used SPSS (Chicago, IL, USA) statistical software, version 17, for analysis. Fisher's exact test was applied to assess the relationship between EGFR mutation status and clinicopathological categorical characteristics. A two-tailed p-value $<0.05$ was considered statistically significant. The censored 5 -yr overall survival time after surgical resection was estimated using the Kaplan-Meier method and survival differences were analysed using the log-rank test. 


\section{RESULTS}

\section{Subject characteristics}

We evaluated 522 resected lung tumour samples and a subset of 64 matched serum samples. There were 345 males and 177 females, 487 current or former smokers and 35 never-smokers. There were 294 subjects with adenocarcinoma, 161 subjects with squamous cell carcinomas, 32 subjects with large cell carcinoma and 35 subjects with adenosquamous carcinoma. Pathological staging revealed that 259 (49\%) subjects had stage I, $140(27 \%)$ subjects had stage II, 108 (21\%) subjects had stage III and $15(3 \%)$ subjects had stage IV NSCLC. Non-Aboriginal (inferred to be Caucasian) ethnicity was reported in 498 subjects, six subjects reported Asian ethnicity, two subjects reported Australian Aboriginal ethnicity and 16 subjects did not report their ethnicity. The clinico-pathological characteristics of the study subjects are listed in table 1.

\section{Dilution studies of ME-PCR and HRM}

We evaluated the DEL and L858R mutant allele detection threshold of ME-PCR and HRM by serially diluting cell line DNA containing heterozygous EGFR mutations with wild-type DNA (fig. 1). For ME-PCR, DEL and L858R mutations were detected in the $50 \%, 10 \%, 5 \%, 2.5 \%$ and $0.5 \%$ dilution mixtures. Using HRM, DEL mutations were detected in $50 \%$ and $10 \%$ mutant allele frequency, but not $5 \%$ or below, and L858R mutations were detected in $50 \%, 10 \%, 5 \%$ and $2.5 \%$, but not $0.5 \%$ allele frequency.

\section{Detection of EGFR mutations in tumour samples}

In the 522 samples, EGFR mutations were detected in 27 samples ( $5 \%$ ) by ME-PCR and HRM and 23 of these samples were EGFR mutation positive by both methods. Additionally, the two methods were concordant for EGFR wild-type in 491 tumour samples.

\section{ME-PCR}

ME-PCR detected 11 DEL mutations and 16 L858R mutations (table 2). Among the DEL mutation samples, DNA sequencing identified c.2235-2249 (p.E746-A750del) in five samples, p.L747-S752del in two samples, p.L747-E749del in one sample, and no DEL mutation was detected in three samples. In the 16 L858R mutation-positive samples, DNA sequencing identified the L858R in 15 samples, and no mutation could be detected in one sample.

\section{HRM}

HRM identified exon 19 DEL mutations in nine samples and exon 21 mutations in 18 samples (table 2). Among the DELpositive samples, DNA sequencing identified c.2235-2249 (p.E746-A750del) in five samples, p.L747-S752del in two samples, p.L747-E749del in one sample, and no DEL mutation could be detected in one sample. In the exon 21 mutationpositive samples, DNA sequencing identified L858R in 14 samples, L861Q in one sample, R486K in one sample, P848L in one sample, and no exon 21 mutation in one sample.

\section{Comparison of ME-PCR and HRM}

The diagnostic accuracy of ME-PCR and HRM was determined by comparing the results against DNA sequencing in a cohort of 97 samples, where EGFR mutations were detected in $9 \%$ (nine

\begin{tabular}{|c|c|c|c|}
\hline Characteristics & Total & $\begin{array}{c}\text { EGFR wild- } \\
\text { type }\end{array}$ & $\begin{array}{c}\text { EGFR } \\
\text { mutation }^{\#}\end{array}$ \\
\hline Subjects & 522 & 496 & 26 \\
\hline \multicolumn{4}{|l|}{ Sex } \\
\hline Male & 345 & 337 (68) & $8(31)$ \\
\hline Female & 177 & 159 (32) & $18(69)$ \\
\hline Age yrs & $65(33-85)$ & $66(33-85)$ & $65(30-82)$ \\
\hline \multicolumn{4}{|l|}{ Ethnicity } \\
\hline Caucasian & 498 & $475(95.5)$ & $23(88)$ \\
\hline Asian & 6 & $4(1)$ & $2(8)$ \\
\hline Indigenous & 2 & $2(0.5)$ & \\
\hline Not stated/unknown & 16 & $15(3)$ & $1(4)$ \\
\hline \multicolumn{4}{|l|}{ Smoking history } \\
\hline Never & 35 & $27(5)$ & $9(35)$ \\
\hline Former & 64 & $62(13)$ & $2(8)$ \\
\hline Current & 425 & 407 (82) & $15(57)$ \\
\hline Median pack-yrs & 44 & 40 & 18 \\
\hline Tumour size mm & $40(5-110)$ & $40(5-110)$ & $32(18-75)$ \\
\hline \multicolumn{4}{|l|}{ Tumour differentiation } \\
\hline Well to moderate & 259 & $244(49)$ & $15(58)$ \\
\hline Poor & 263 & $252(51)$ & $11(42)$ \\
\hline \multicolumn{4}{|l|}{ Histological diagnosis } \\
\hline Adenocarcinoma & 294 & $273(55)$ & $21(81)$ \\
\hline Squamous cell carcinoma & 161 & 159 (32) & $2(8)$ \\
\hline Large cell carcinoma & 32 & $31(6)$ & $1(4)$ \\
\hline Adenosquamous carcinoma & 35 & $33(7)$ & $2(7)$ \\
\hline \multicolumn{4}{|l|}{ Stage } \\
\hline$|A| B$, & 259 & $255(51)$ & $6(23)$ \\
\hline$\|A\| B$, & 140 & $127(26)$ & $11(42)$ \\
\hline$\| \mathrm{A}$, IIIB & 108 & $99(20)$ & $9(35)$ \\
\hline IV & 15 & $15(3)$ & \\
\hline Follow-up months & $28(1-215)$ & $28(1-215)$ & $23(1-103)$ \\
\hline \multicolumn{4}{|l|}{ Survival status } \\
\hline Alive & 228 & $215(43)$ & $13(50)$ \\
\hline Dead & 294 & $281(57)$ & $13(50)$ \\
\hline $\begin{array}{l}\text { Data are presented as } n, n(\%) \\
\text { factor receptor. }{ }^{\#} \text { : EGFR mutati } \\
\text { in all study subjects; } \because \text { : pathol } \\
\text { Committee on Cancer staging }\end{array}$ & $\begin{array}{l}\text { dian (range). } \\
\text { s confirmed } \\
\text { tage accord } \\
\text { sixth edition }\end{array}$ & $\begin{array}{l}\text { EGFR: epide } \\
\text { by direct DNA } \\
\text { ling to the An } \\
{[22] \text {. }}\end{array}$ & $\begin{array}{l}\text { rmal growth } \\
\text { sequencing } \\
\text { erican Joint }\end{array}$ \\
\hline
\end{tabular}

out of 97). ME-PCR had a sensitivity of $100 \%$ and specificity of $99 \%$, and HRM had a sensitivity and specificity of $100 \%$.

\section{Detection of EGFR mutations in serum}

In a subset of 64 subjects, EGFR mutation testing was performed on matched tumour tissue and serum. EGFR mutations were detected in six tumour samples (DEL in two samples and L858R in four samples) and EGFR wild-type in 58 tumour samples. In the matched serum samples of two DEL mutation tumour samples, ME-PCR and HRM identified the DEL mutation in only one of the samples. In the four L858Rpositive tumour samples, ME-PCR detected the corresponding mutation in two matched serum samples and HRM detected the corresponding mutations in only one matched serum sample (table 3). 

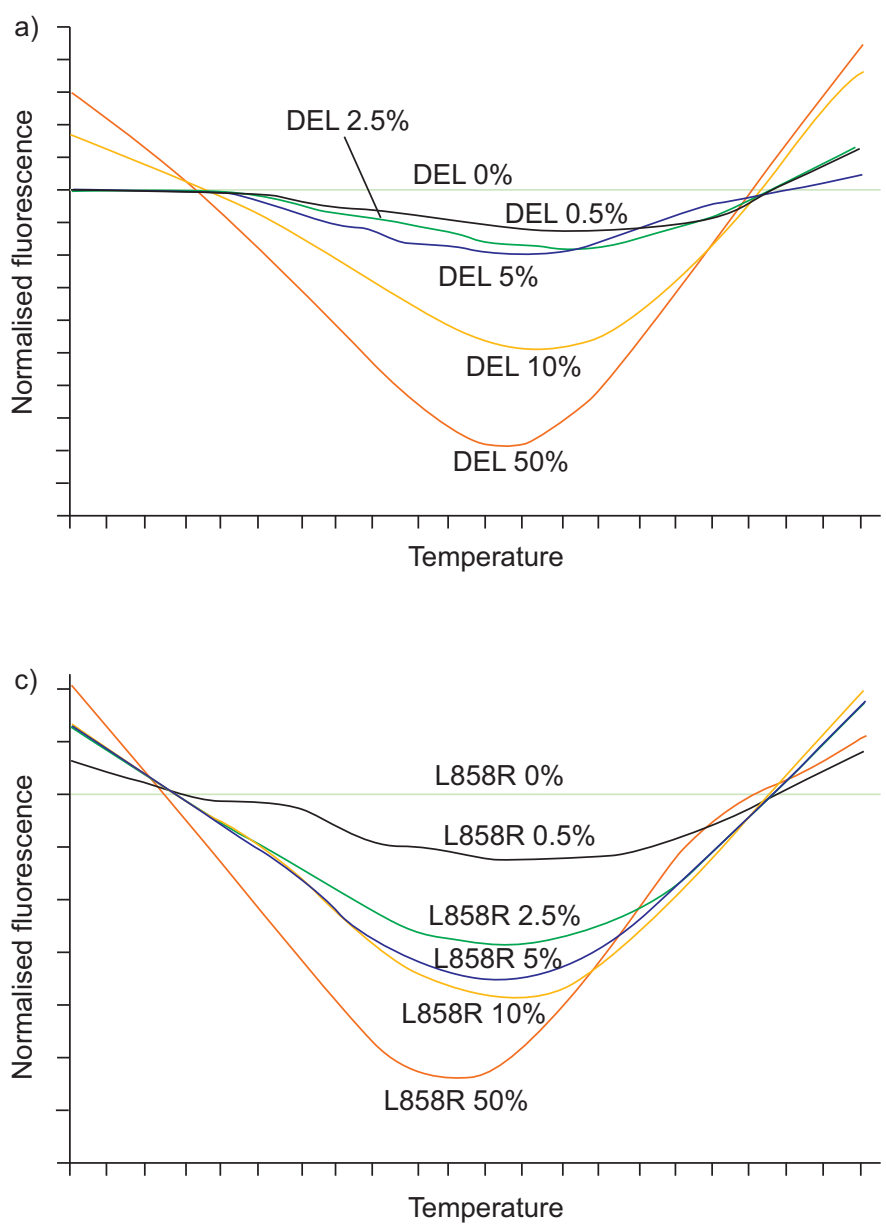

b)

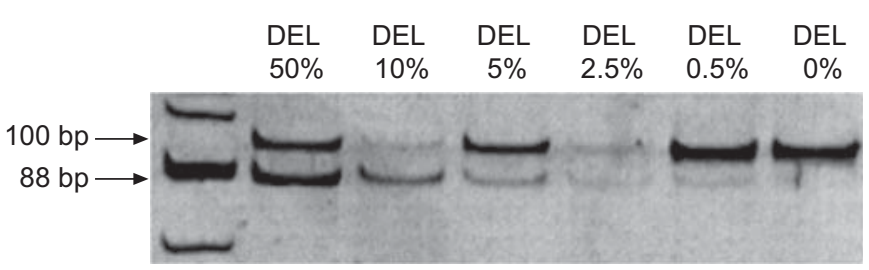

d)

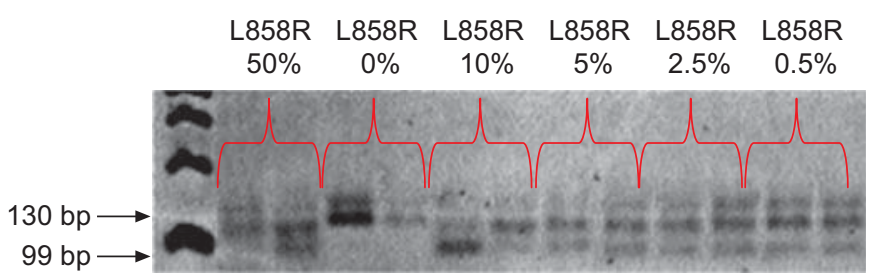

FIGURE 1. Determination of sensitivity for epidermal growth factor receptor (EGFR) exon $19 \mathrm{DEL}$ and exon 21 L858R by high-resolution melt analysis (a and c) and mutation-enriched PCR assay (b and d). Adenocarcinoma cell lines containing EGFR exon 19 DEL (H1650) and exon 21 L858R (H1975) were mixed with pooled genomic DNA (EGFR wild-type) to produce dilutions of $50 \%, 10 \%, 5 \%, 2.5 \%, 0.5 \%$ and $0 \%$ (wild-type) dilutions. a) Difference plots obtained by high-resolution melting analysis identified $50 \%$ and $10 \%$ dilution samples as containing the DEL mutation. b) The bands of 88 bp indicate exon 19 DEL mutant alleles, and bands of 100 bp indicate wild-type alleles. The exon $19 \mathrm{DEL}$ allele was detected in the $50 \%, 10 \%, 5 \%, 2.5 \%$ and $0.5 \%$ dilutions. c) Difference plots obtained by high-resolution melting analysis identified $50 \%$, $10 \%, 5 \%$ and $2.5 \%$ dilution samples as containing the L858R mutation. d) The bands of 99 bp indicate exon 21 L858R mutant alleles, and bands of 130 bp indicate wild-type alleles. The exon $21 \mathrm{~L} 858 \mathrm{R}$ allele was detected in the 50\%, 10\%, 5\%, 2.5\% and $0.5 \%$ dilutions.

\section{Clinico-pathological parameters and survival analysis}

We evaluated the relationship between the tumour EGFR mutation status, as determined by ME-PCR and HRM with clinico-pathological parameters. EGFR mutations were detected more frequently in never-smokers versus smokers (27\% versus $3.5 \% ; \mathrm{p}<0.001)$, females versus males ( $10 \%$ versus $2.3 \% ; \mathrm{p}<0.001)$, adenocarcinoma histology versus non-adenocarcinoma histology ( $7 \%$ versus $2.5 \% ; \mathrm{p}=0.039)$ and Asian versus non-Asian ethnicity ( $33 \%$ versus $5 \% ; \mathrm{p}=0.031$ ).

We also examined the relationship of clinico-pathological parameters, EGFR mutation status and overall survival at 5 yrs post-surgery. The follow-up duration was calculated from the date of surgical resection. The two variables that were associated with survival differences were tumour stage $(p<0.001)$ and differentiation $(p=0.005)$, while there were no survival differences between adenocarcinoma and squamous cell carcinoma histological subtypes $(p=0.272)$ or between the $<65$ yrs and $>65$ yrs age groups $(p=0.837)$ (fig. 1 , online supplementary material). There was a trend towards better survival among never-smokers compared to ever-smokers, but this difference did not reach statistical significance (44 months versus 39 months; $\mathrm{p}=0.158$ ). The median survival time for subjects with EGFRmutated tumours was 34 months compared with 45 months for subjects with EGFR wild-type tumours; however, this difference was not significant ( $\mathrm{p}=0.966)$ (fig. 2). In never-smokers, EGFR mutation status was associated with worse survival compared to wild-type status (30 months versus 49 months; $p=0.017$ ), while there was no difference in survival between smokers with EGFR mutant and wild-type tumours (43 months versus 39 months; $\mathrm{p}=0.400$ ) (fig. 2).

\section{DISCUSSION}

Currently, a clinico-pathological model, i.e. the tumour node metastases (TNM) system, remains the most reliable predictor of prognosis in surgically resected NSCLC [23]. Recent molecular NSCLC genomic studies have provided refinements to the TNM prognosis models [24]. However, these methods have not yet been demonstrated to predict therapeutic responsiveness and have not been validated in prospective studies. Conversely, 
TABLE 2 Characteristics of patients with epidermal growth factor receptor (EGFR) mutations

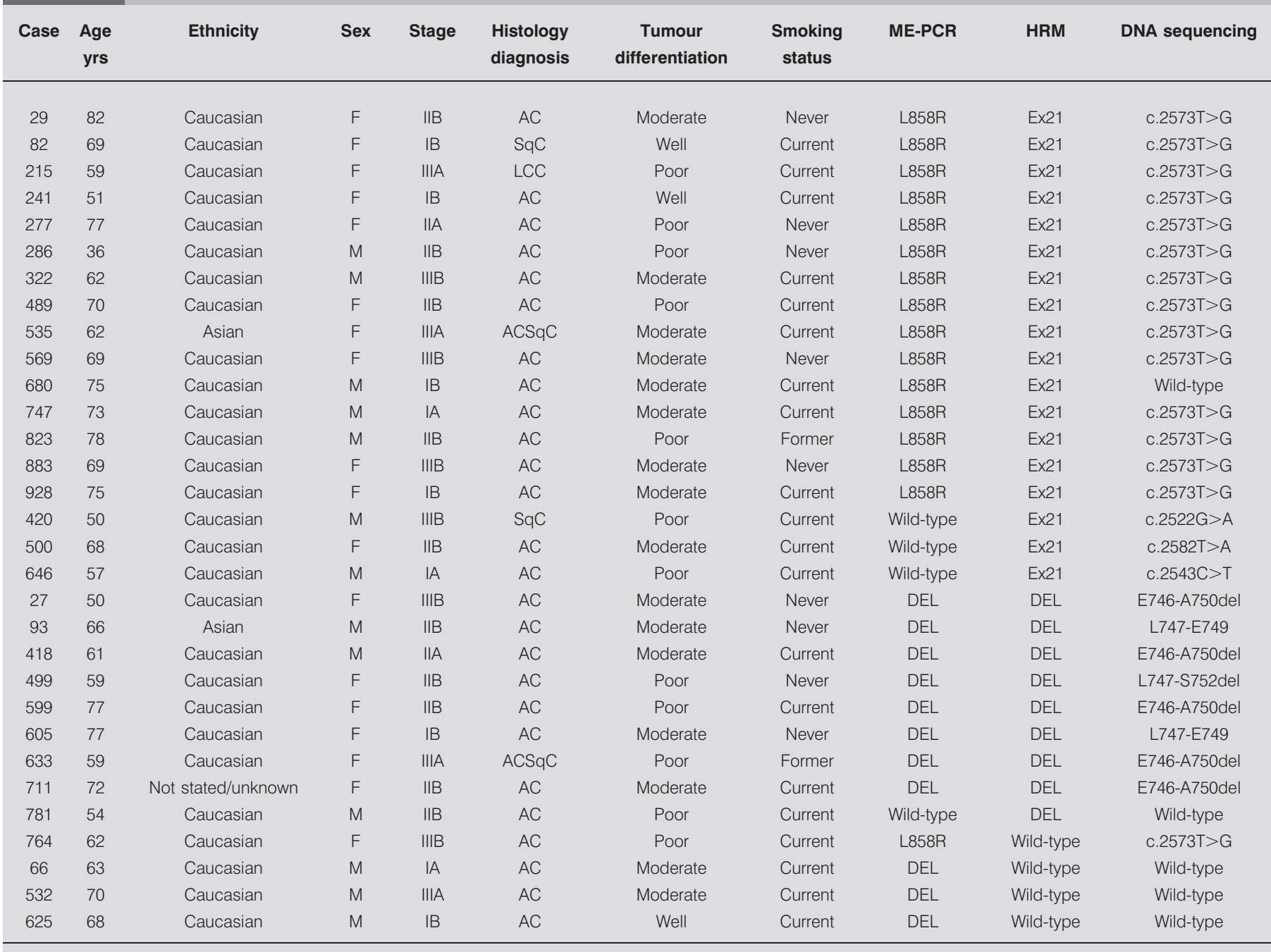

ME: mutant-enriched; HRM: high-resolution melt; F: female; M: male; AC: adenocarcinoma; SqC: squamous cell carcinoma; LCC: large cell carcinoma; ACSqC: adenosquamous cell carcinoma. EGFR mutation status was confirmed by direct DNA sequencing in all study subjects.

\begin{tabular}{lcc} 
TABLE 3 & $\begin{array}{l}\text { Comparison of detection of epidermal growth } \\
\text { factor receptor }(E G F R) \\
\text { serum and tumour tissue }\end{array}$ \\
\cline { 2 - 3 } Serum & \multicolumn{2}{c}{ Tumour $^{\#}$} \\
\cline { 2 - 3 } & Mutation & Wild-type \\
\hline $\begin{array}{l}\text { Total } \\
\text { ME-PCR } \\
\text { Mutation } \\
\text { Wild-type }\end{array}$ & 6 & 58 \\
HRM & 3 & 0 \\
Mutation & 3 & 58 \\
Wild-type & $2^{*}$ & 0 \\
\hline & $4^{+}$ & 58 \\
\hline
\end{tabular}

ME: mutant-enriched; HRM: high-resolution melt. \#: EGFR mutation status determined by ME-PCR, HRM and DNA sequencing; " : both of the samples were also EGFR mutation positive by ME-PCR; ${ }^{+}$: three of the samples were also EGFR mutation positive by ME-PCR. determining the EGFR mutation status of advanced NSCLC tumours can be applied to predict the response to TKIs and standard chemotherapy, a strategy that has recently been validated in prospective clinical studies [4,5]. While contemporary clinical practice consists of screening subjects with advanced NSCLC for EGFR mutations, the benefit of adopting a similar practice in the management of subjects with surgically resected NSCLC remains to be established.

In the management of subjects with surgically resected NSCLC and the current era of TKIs, one approach may be to screen for EGFR mutations only in subjects with recurrence of the primary malignancy. However, such a strategy implies that TKIs will not be utilised as adjuvant therapy to prevent recurrence of the primary malignancy. Hence it may be more beneficial to screen for EGFR mutations in the surgically resected tumour tissue, in order to determine prognosis, and in those subjects with an adverse risk profile to treat with adjuvant TKI or chemotherapy, in order to improve their outcomes. In this study, we found that when considering all 

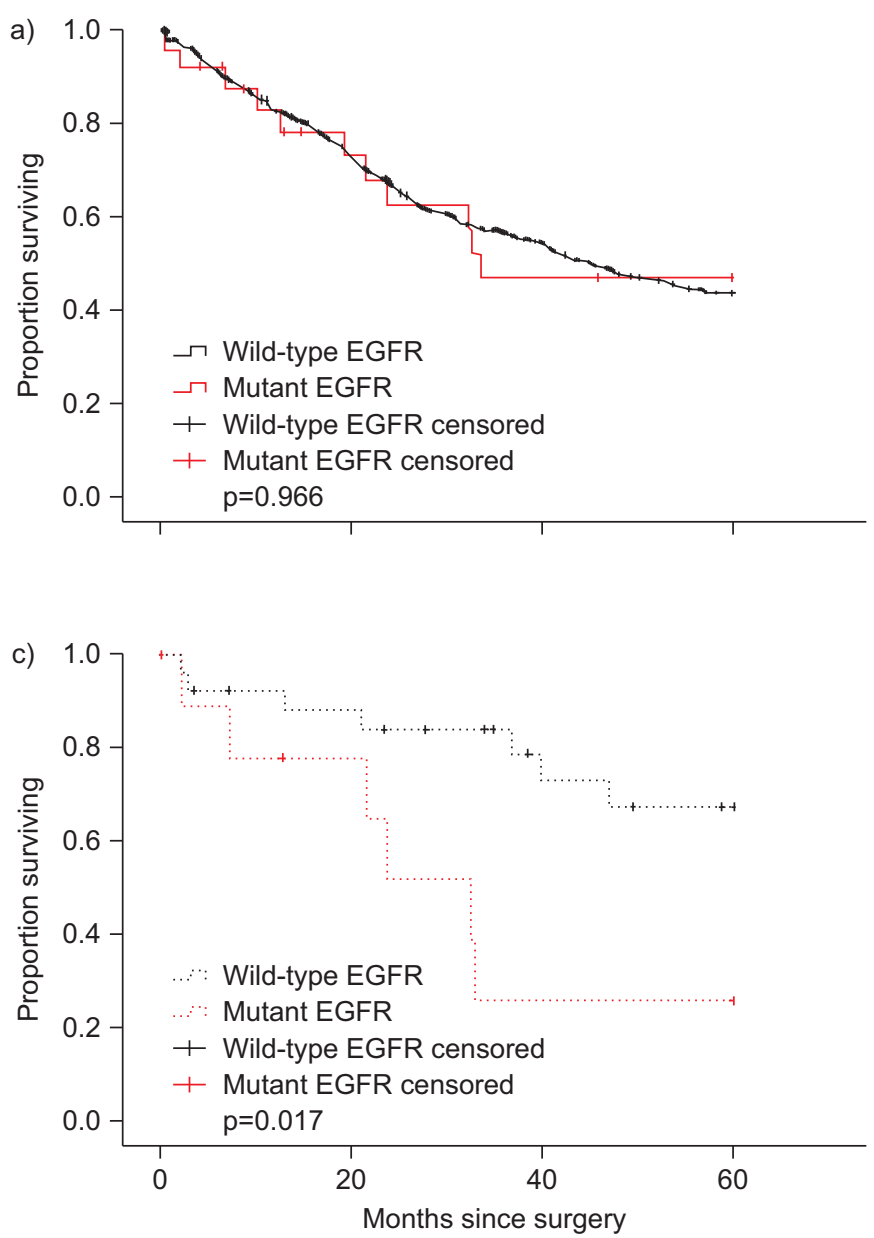

b)

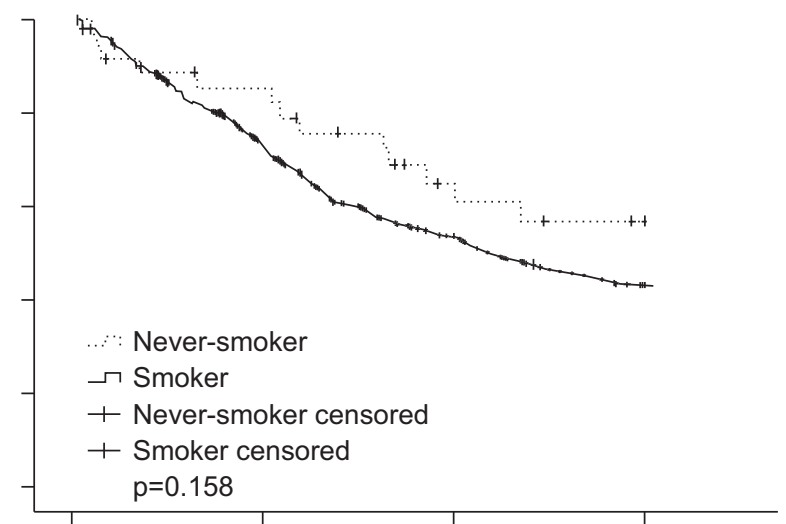

d)

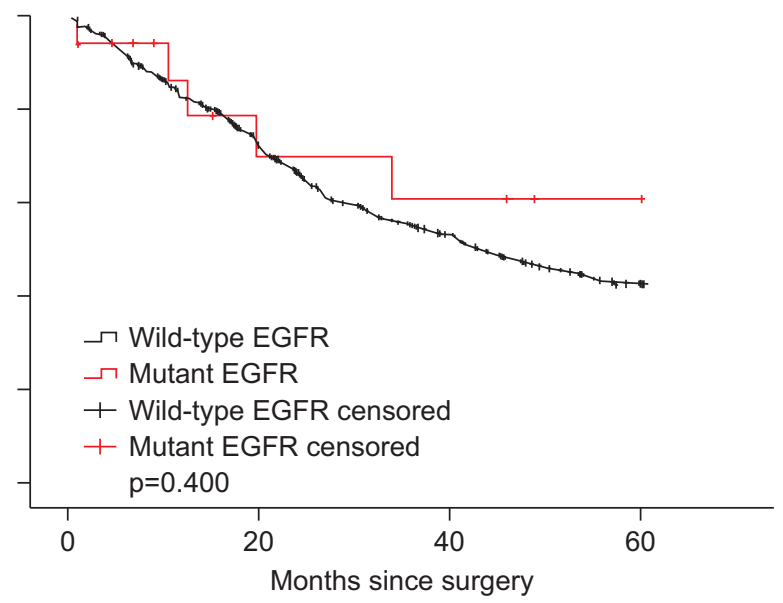

FIGURE 2. Kaplan-Meier survival curves of survival data with follow-up duration of 5 yrs after surgical resection of primary nonsmall cell lung cancers (total $\mathrm{n}=522$ ) Censored values indicate the last known follow-up time for those subjects still alive after surgical resection. a) Subjects with wild-type epidermal growth factor receptor (EGFR) tumours versus mutant EGFR tumours. b) Never-smokers versus smokers. c) Never-smokers with mutant EGFR tumours versus never-smokers with wild-type EGFR tumours d) Smokers with mutant EGFR versus smokers with wild-type EGFR tumours. EGFR mutation status in never-smokers was associated with significant survival differences $\mathrm{p}$-values are from the log-rank test.

subjects with surgically resected NSCLC, EGFR mutation status was not prognostic of overall survival. This is consistent with previously reported data $[10,11,13]$. Interestingly, studies that have demonstrated a survival benefit in EGFR mutation subjects after surgical resection have conflicting results [6, 14]. While MARKS et al. [6] noted a survival benefit at 5 yrs post-surgery on univariate and on multivariate analyses, a subsequent study by LiU et al. [14] was able to find a median survival benefit at 3 yrs post-surgery but not at $5 \mathrm{yrs}$, and on multivariate analyses but not univariate analyses. The survival benefit in the studies by MARKS et al. [6] and LIU et al. [14] may be partly explained by a higher proportion of never-smokers in the cohort of subjects with EGFR mutations, $90 \%$ and $47 \%$ respectively, compared with $35 \%$ in our study. However, we also found that EGFR mutation status is associated with worse prognosis in neversmokers but not among smokers. This interesting finding requires further investigation in a prospective study with a larger sample size of never-smokers. If validated, this observation implies that this group of subjects may be candidates for adjuvant therapy with EGFR TKIs. Our findings are concordant with the growing evidence that molecular changes in neversmokers with lung cancer are characteristically different from those occurring in smokers with lung cancer [25]. This is of major clinical significance globally since $25 \%$ of lung cancer cases worldwide occur in never-smokers [25]. Consequently, screening never-smokers with surgically resected NSCLC for EGFR mutations may not only be prognostic but may also assist in planning adjuvant treatment.

There are currently several methods for performing EGFR mutation testing on NSCLC subject samples, with DNA sequencing being the current gold standard test [16]. However, the cost and technical challenges of DNA sequencing mandate that clinical EGFR mutation testing is performed in only a small proportion of NSCLC subjects. Our study demonstrates that MEPCR and HRM are accurate and can be considered viable alternatives to DNA sequencing in the detection of EGFR mutations in tumour tissue. Either of these relatively inexpensive methods could make routine clinical testing for EGFR mutations practical in all NSCLC patients, particularly in resource-scarce communities, where the incidence of lung cancer is increasing [1].

The EGFR mutation status of 97 subjects from our study cohort has been reported previously [11], in which nine $(9.3 \%)$ 
subjects were EGFR mutation positive. The difference in frequency of EGFR mutation rates between the 97 subjects and the 522 subjects in the current study can be explained by the enriched population of never-smokers in the earlier study ( $34 \%$ versus $7 \%$ ). The current study is a more accurate representation of the general NSCLC patient population in our institution. We found mutation prevalence of $5 \%$ by screening available cases resected for NSCLC at our Australian centre. This is somewhat lower than earlier studies reporting mutations of $10-16 \%[7,26]$, each with differing inclusion criteria for enrolment. However, our data is consistent with these other studies in that higher mutation frequencies were observed in never-smokers (33\%), subjects of Asian ethnicity $(33 \%)$, females $(10 \%)$ and those with adenocarcinoma histology $(7 \%)$. Therefore, the relatively low mutation frequency may simply reflect the predominance in our subject group of Caucasian male smokers, who accounted for $64 \%$ of the study cohort and in whom the mutation frequency was $2 \%$.

In real-life clinical scenarios, the amount of primary tumour tissue available for molecular testing is often limited and, hence, a clinically applicable test should ideally also be able to detect mutations in blood samples. Cell free DNA contained in blood is most likely released from either necrotic tumour cells and/or DNA from circulating tumour cells. Recent studies have found that EGFR mutations in the serum of NSCLC subjects are also predictive of responsiveness to TKIs [27]. In two out of six subjects in our study, HRM was also able to detect the same mutation in both serum and tumour tissue. ME-PCR confirmed the findings in the two serum samples. This finding suggests that, similar to ME-PCR [19], HRM may also be a useful screening test for EGFR mutations in serum samples. The role of screening serum for EGFR mutations in subjects with surgically resected NSCLC, in whom there is usually adequate tumour tissue available for mutation testing, may be in detecting recurrence or residual disease and monitoring response to adjuvant therapy with TKIs in cases of EGFR mutation-positive tumours.

In our study, we have screened only for the most common activating EGFR mutations, i.e. DEL and L858R. There is a growing catalogue of EGFR mutations in NSCLC which have considerably less frequency than the DEL and L858R mutations [28]. Screening tests are designed to detect only known mutations, as compared to DNA sequencing, which can detect both known and unknown mutations. Since we have screened only for the most common activating mutations, it is conceivable that we have overlooked other mutations, albeit less common, which may have prognostic implications in surgically resected NSCLC. Another shortcoming of our study is the disproportionately small number of subjects with matched serum and tumour tissue (12\%). This limits our ability in making firm conclusions about the reliability and accuracy of ME-PCR and HRM in detecting EGFR mutations in serum samples. We are overcoming this limitation by modifying our biobank collection protocols to ensure that matched serums are collected from all patients who undergo surgical resection of NSCLC.

In summary, our study suggests that, although the presence of activating EGFR mutations is not prognostic in smokers, it is associated with worse survival in never-smoker subjects with surgically resected NSCLC. Confirmatory studies will need to be performed, particularly in a large cohort of never-smoker subjects. Consequently, we are planning a large-scale prospective screen for EGFR mutations in surgically resected NSCLC, consisting of never-smokers and smokers, to validate the findings of our current study. We have also demonstrated that ME-PCR and HRM are reliable alternatives to DNA sequencing in the detection of activating EGFR mutations in tumour tissue. Additionally, HRM is comparable to ME-PCR, a highly sensitive method, in being able to detect EGFR mutations in tissue and serum. Since ME-PCR and HRM are both technically simple and high-throughput methods, they can be conveniently established in most pathology laboratories, thus enabling EGFR mutation testing to be more readily incorporated into clinical practice than is possible with DNA sequencing. Such a strategy will enable inexpensive routine testing for EGFR mutations in both surgically resected and advanced NSCLC subjects and will contribute to the delivery of personalised cancer prognosis and treatment plans.

\section{SUPPORT STATEMENT}

This study was supported by: NH\&MRC and Queensland Smart State project grants; NH\&MRC Postgraduate Medical Scholarship (K.B. Sriram), NH\&MRC Practitioner Fellowship (K.M. Fong), NH\&MRC Career Development Award (I.A. Yang), NH\&MRC Biomedical Scholarship (S.M. Savarimuthu and C.M. Wright), Cancer Council Queensland Senior Research Fellowship (K.M. Fong), Queensland Clinical Research Fellowship (K.M. Fong and I.A. Yang) and The Prince Charles Hospital Foundation.

\section{STATEMENT OF INTEREST}

None declared.

\section{ACKNOWLEDGEMENTS}

The authors wish to thank A. Dobrovic and H. Do (Peter MacCallum Cancer Institute, Melbourne, Australia) for providing H1650 and H1975 cell line DNA, the patients of The Prince Charles Hospital, Brisbane, Australia for their participation in this study and The Prince Charles Hospital surgeons, pathologists, scientists and thoracic research laboratory staff for their assistance with specimen collection.

\section{REFERENCES}

1 Parkin DM, Bray F, Ferlay J, et al. Global Cancer Statistics, 2002. CA Cancer J Clin 2005; 55: 74-108.

2 Hoffman PC, Mauer AM, Vokes EE. Lung cancer. Lancet 2000; 355: 479-485.

3 Pisters KMW, Evans WK, Azzoli CG, et al. Cancer Care Ontario and American Society of Clinical Oncology adjuvant chemotherapy and adjuvant radiation therapy for stages I-IIIA resectable non-small-cell lung cancer guideline. J Clin Oncol 2007; 25: 5506-5518.

4 Maemondo M, Inoue A, Kobayashi K, et al. Gefitinib or chemotherapy for non-small-cell lung cancer with mutated EGFR. $N$ Engl J Med 2010; 362: 2380-2388.

5 Mok TS, Wu Y-L, Thongprasert S, et al. Gefitinib or carboplatinpaclitaxel in pulmonary adenocarcinoma. N Engl J Med 2009; 361: 947-957.

6 Marks JL, Broderick S, Zhou Q, et al. Prognostic and therapeutic implications of EGFR and KRAS mutations in resected lung adenocarcinoma. J Thorac Oncol 2008; 3: 111-116.

7 Sharma SV, Bell DW, Settleman J, et al. Epidermal growth factor receptor mutations in lung cancer. Nat Rev Cancer 2007; 7: 169-181. 
8 Gazdar AF. Activating and resistance mutations of EGFR in nonsmall-cell lung cancer: role in clinical response to EGFR tyrosine kinase inhibitors. Oncogene 2009; 28: Suppl. 1, S24-S31.

9 Tsao M-S, Sakurada A, Ding K, et al. Prognostic and predictive value of epidermal growth factor receptor tyrosine kinase domain mutation status and gene copy number for adjuvant chemotherapy in non-small cell lung cancer. J Thorac Oncol 2011; 6: 139-147.

10 Sugio K, Uramoto H, Ono K, et al. Mutations within the tyrosine kinase domain of EGFR gene specifically occur in lung adenocarcinoma patients with a low exposure of tobacco smoking. $\mathrm{Br} \mathrm{J}$ Cancer 2006; 94: 896-903.

11 Shigematsu $\mathrm{H}$, Lin $\mathrm{L}$, Takahashi $\mathrm{T}$, et al. Clinical and biological features associated with epidermal growth factor receptor gene mutations in lung cancers. J Natl Cancer Inst 2005; 97: 339-346.

12 Kosaka T, Yatabe Y, Endoh $\mathrm{H}$, et al. Mutations of the epidermal growth factor receptor gene in lung cancer: biological and clinical implications. Cancer Res 2004; 64: 8919-8923.

13 Kosaka T, Yatabe Y, Onozato R, et al. Prognostic implication of EGFR, KRAS, and TP53 gene mutations in a large cohort of Japanese patients with surgically treated lung adenocarcinoma. J Thorac Oncol 2009; 4: 22-29.

14 Liu H-P, Isaac Wu H-D, Chang JW-C, et al. Prognostic implications of epidermal growth factor receptor and KRAS gene mutations and epidermal growth factor receptor gene copy numbers in patients with surgically resectable non-small cell lung cancer in Taiwan. J Thorac Oncol 2010; 5: 1175-1184.

15 Suehisa H, Toyooka S, Hotta K, et al. Epidermal growth factor receptor mutation status and adjuvant chemotherapy with uracil-tegafur for adenocarcinoma of the lung. J Clin Oncol 2007; 25: 3952-3957.

16 Pao W, Ladanyi M. Epidermal growth factor receptor mutation testing in lung cancer: searching for the ideal method. Clin Cancer Res 2007; 13: 4954-4955.

17 Maheswaran S, Sequist LV, Nagrath S, et al. Detection of mutations in EGFR in circulating lung-cancer cells. N Engl J Med 2008; 359: 366-377.
18 Asano H, Toyooka S, Tokumo M, et al. Detection of EGFR gene mutation in lung cancer by mutant-enriched polymerase chain reaction assay. Clin Cancer Res 2006; 12: 43-48.

19 He C, Liu M, Zhou C, et al. Detection of epidermal growth factor receptor mutations in plasma by mutant-enriched PCR assay for prediction of the response to gefitinib in patients with non-smallcell lung cancer. Int J Cancer 2009; 125: 2393-2399.

20 Do $\mathrm{H}$, Krypuy $\mathrm{M}$, Mitchell $\mathrm{P}$, et al. High resolution melting analysis for rapid and sensitive EGFR and KRAS mutation detection in formalin fixed paraffin embedded biopsies. BMC Cancer 2008; 8: 142.

21 Sordella R, Bell DW, Haber DA, et al. Gefitinib-sensitizing EGFR mutations in lung cancer activate anti-apoptotic pathways. Science 2004; 305: 1163-1167.

22 American Joint Committee on Cancer Staging. Manual for Staging of Cancer, 6th Edn. Philadelphia, J.B. Lippincott, 2002.

23 Birim Ö, Kappetein AP, van Klaveren RJ, et al. Prognostic factors in non-small cell lung cancer surgery. Eur J Surg Oncol 2006; 32: 12-23.

24 Sriram KB, Larsen JE, Yang IA, et al. Genomic medicine in nonsmall cell lung cancer: paving the path to personalized care. Respirology 2011; 16: 257-263.

25 Sun S, Schiller JH, Gazdar AF. Lung cancer in never smokers - a different disease. Nat Rev Cancer 2007; 7: 778-790.

26 Rosell R, Moran T, Queralt C, et al. Screening for epidermal growth factor receptor mutations in lung cancer. N Engl J Med 2009; 361 958-967.

27 Bai H, Mao L, Wang HS, et al. Epidermal growth factor receptor mutations in plasma DNA samples predict tumor response in Chinese patients with stages IIIB to IV non-small-cell lung cancer. J Clin Oncol 2009; 27: 2653-2659.

28 Linardou H, Dahabreh IJ, Bafaloukos D, et al. Somatic EGFR mutations and efficacy of tyrosine kinase inhibitors in NSCLC. Nat Rev Clin Oncol 2009; 6: 352-366. 